\title{
UTILISATION D'UN SYSTĖME TRIS-GLYCOCOLLE POUR TAMPONNER LE DILUEUR D'INSÉMINATION POUR TRUITE
}

\author{
par R. BILLARD \\ Laboratoire de Physiologie des Poissons \\ I.N.R.A., 78350 JOUY-EN-JOSAS, France
}

\section{INTRODUCTION}

L'avantage des solutions salines pour l'insémination artificielle des Salmonidés est connu depuis longtemps, mais elles n'avaient jamais été utilisées couramment en salmoniculture. La démonstration de l'effet favorable de $\mathrm{pH}$ relativement élevés ( $\mathrm{pH} 9$ à 9,5) (PETIT et al., 1973) et l'utilisation de tampon à base de carbonate-bicarbonate pour stabiliser ce pH (BILLARD et al., 1974) ont conduit à la fabrication d'un dilueur utilisable en pisciculture. Le dilueur est préparé extemporanément par addition d'eau qui doit nécessairement être distillée. compte tenu de la nature du tampon et des risques de précipitation que présenterait l'emploi d'eaux minéralisées. La difficulté de disposer dans la pratique d'eau distillée et le fait que le bicarbonate est susceptible de se décomposer à la température ambiante nous ont conduit à rechercher un tampon susceptible d'être mélangé directement à l'eau de source ou de rivière dans laquelle l'incubation sera pratiquée. Les investigations ont porté sur un système tampon organique à base de glycocolle dont l'effet favorable sur la conservation de la fécondance du sperme de Truite avait précédemment été montré (BILLARD et al., 1974b).

\section{MATERIEL ET METHODES}

Les conditions générales d'insémination et d'incubation en lots expérimentaux ont été décrites dans les publications précédentes (BILLARD et al., 1974a, 1974b). Les géniteurs mâles et femelles (Salmo gairdneri) proviennent de piscicultures privées et entrent au laboratoire avant la periode de reproduction. Les effets des dilueurs sur la survie du sperme ont été testés par les techniques de simple et double dilution (BILLARD et JALABERT, 1974). 
Brièvement le sperme est mélangè aux différents dilueurs et l'ensemble sperme-dilueur est ajouté aux ovules secs (technique de simple dilution) ou prealablement dilués dans le dilueur d'insemination (technique de double dilution). Les dilueurs d'insémination utilisés sont à base de $\mathrm{NaCl}$ et caractérisés par une pression osmotique finale (posm) de 250 mosmol et un $\mathrm{pH}$ de 9,0. Le systeme carbonate-bicarbonate $0,02 \mathrm{M}$ final (BILLARD et al., 1974b) a été utilisé comme tampon de référence et comparé au système Tris-glycocolle de molarités respectives variables (cf. Fig. 1). D'autres dilueurs décrits précédemment ont été utilisés (reconstitution minérale du liquide séminal: MMLS) (BILLARD et JALABERT, 1974), ainsi que du liquide coelomique naturel, du plasma sanguin et un milieu synthétique balancé (Milieu B 2) utilisé pour les culutres de follicules de Mammifères (MENEZO, 1976).

Les effets des différents dilueurs sont mesurés par le pourcentage de fécondation. Ce dernier établi à 100 degrés-jour, c'est-à-dire après incubation des œufs à $10^{\circ} \mathrm{C}$ pendant 10 jours, correspond en réalité au pourcentage d'œufs embryonnés, mais représente assez fidèlement le pourcentage de fécondation.

L'analyse statistique est faite par analyse de variance ou test $t$, après transformation angulaire des pourcentages.

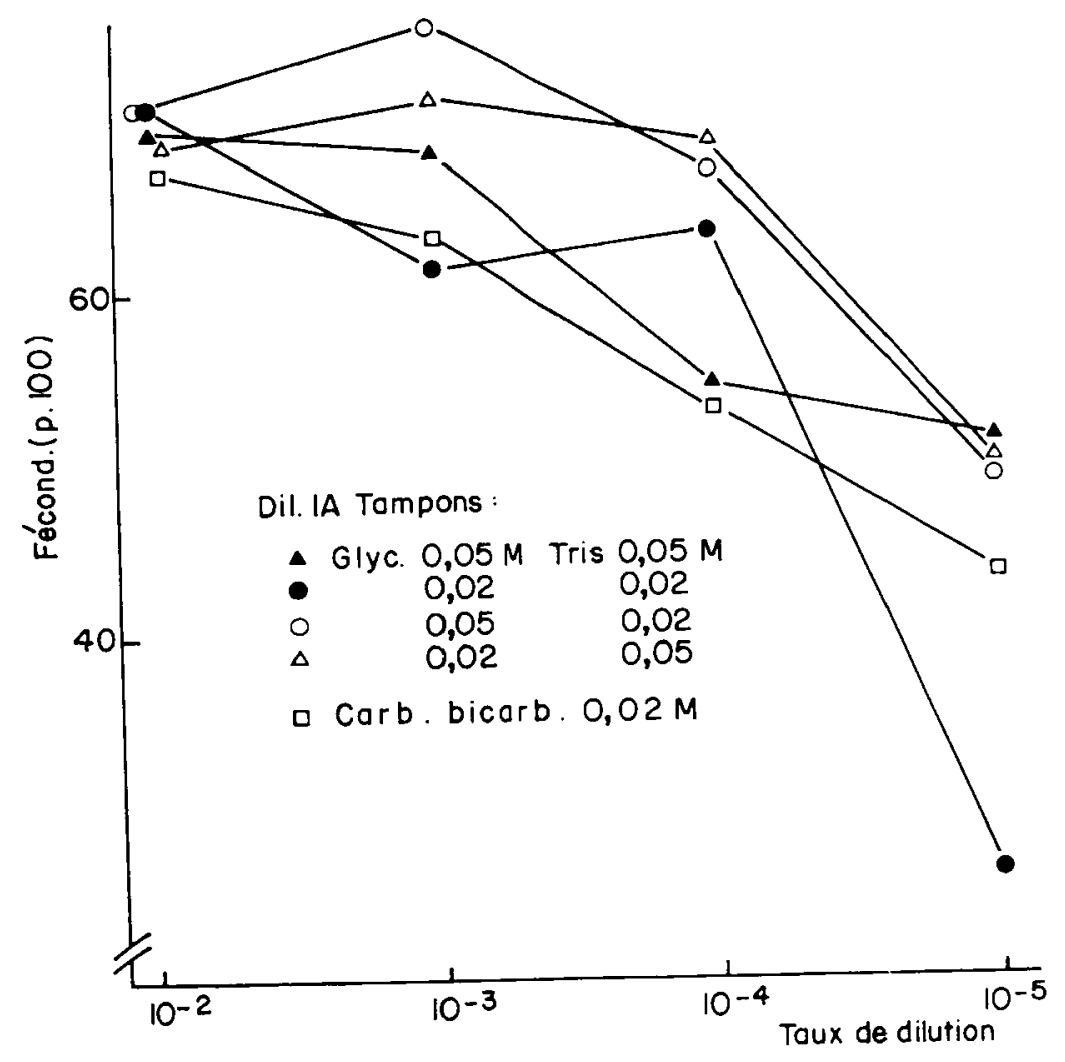

Figure 1 - Evolution du pourcentage de fécondation obtenu après insémination d'ovules dans un dilueur dont le $\mathrm{pH}$ est stabilisé par des tampons différents Tris-glycocolle et carbonate-bicarbonate. 


\section{RESULTATS}

A. - Utilisation du système tampon Tris-glycocolle à différentes molarités dans le dilueur d'insémination et effet sur le pourcentage de fécondation

Les comparaisons entre les systèmes Tris-glycocolle et Carbonate-bicarbonate sont présentées dans la figure 1. Les résultats sont légèrement supérieurs avec le système Tris-glycocolle utilisé aux molarités intermédiaires 0,05-0,02 $\mathrm{M}$, mais l'analyse de variance ne montre pas d'effet significatif dû au système tampon.

Une comparaison entre deux dilueurs différents tamponnés avec glycocolle $0,05 \mathrm{M}$ et Tris $0,02 \mathrm{M}$ et le système Carbonate-bicarbonate de référence montre aussi (Fig. 2) une légère supériorité du dilueur tamponné par le Tris-glycocolle. sans que l'analyse de variance ne permette de dégager un effet dû au dilueur.

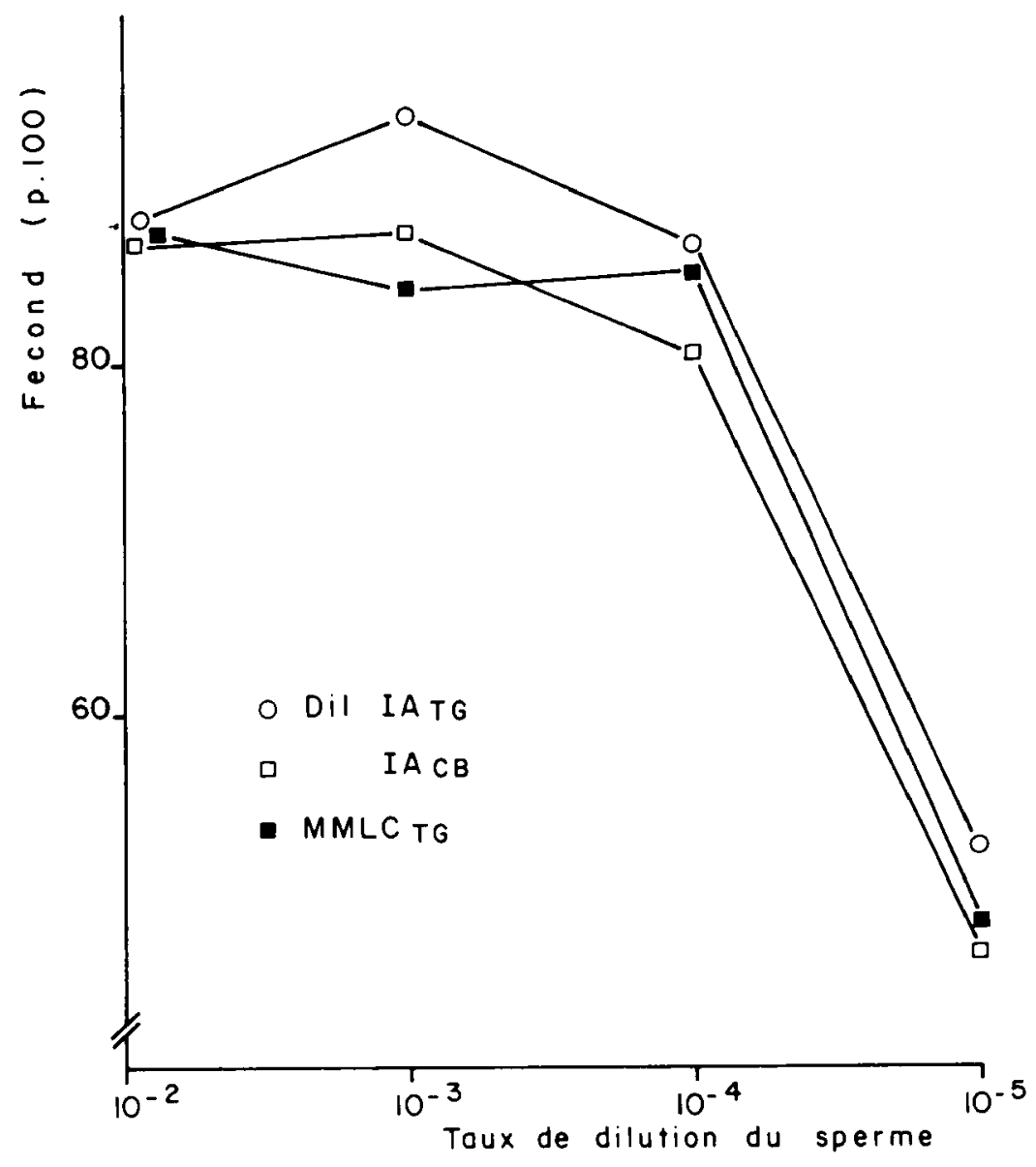

Figure 2 - Pourcentage de fécondation observé après utilisation de différents dilueurs pour l'insémination.

DIAtci et $\mathrm{CB}$ : dilueur d'insémination à base de $\mathrm{NaCl}$ posm 250, pH 9 , systeme tampon Tris C.C2 M-glycocolle $0.05 \mathrm{M}$ ( $\mathrm{rG}$ ) e: carbonate-bica:bonate $(\mathrm{CB})$. 
B - Effet du système tampon sur la survie des spermatozoïdes (Fig. 3)

La conservation du pouvoir fécondant est meilleure dans le dilueur tamponné avec le système Tris-glycocolle que dans le dilueur où le carbonate-bicarbonate a servi de tampon. L'effet dilueur est hautement significatif pour les taux de dilution de $10^{-3}$ et $10^{-4}$ (tableau 1 ).

\begin{tabular}{|c|c|c|c|c|c|}
\hline dilution & & $\mathrm{dl}$ & $\begin{array}{c}\text { Somme des } \\
\text { carrés }\end{array}$ & Carré moyen & $\mathrm{F}$ \\
\hline $10^{-2}$ & $\begin{array}{l}\text { dilueur } \\
\text { temps } \\
\text { résiduelle }\end{array}$ & $\begin{array}{r}4 \\
3 \\
12\end{array}$ & $\begin{array}{r}415.40 \\
1076.40 \\
1042.60\end{array}$ & $\begin{array}{c}103.85 \\
358.80 \\
86.88\end{array}$ & $\begin{array}{l}1.20 \\
4.13^{\star} \\
-\end{array}$ \\
\hline $10^{-3}$ & $\begin{array}{l}\text { dilueur } \\
\text { temps } \\
\text { résiduelle }\end{array}$ & $\begin{array}{r}4 \\
3 \\
12\end{array}$ & $\begin{array}{r}3929.80 \\
648.55 \\
870.20\end{array}$ & $\begin{array}{r}982.45 \\
216.18 \\
75.52\end{array}$ & $\begin{array}{c}13.01^{\star \star \star} \\
2.86 \\
-\end{array}$ \\
\hline $10^{-4}$ & $\begin{array}{c}\text { dilueur } \\
\text { temps } \\
\text { résiduelle }\end{array}$ & $\begin{array}{r}4 \\
3 \\
12\end{array}$ & $\begin{array}{l}4029.95 \\
1338.00 \\
1030.25\end{array}$ & $\begin{array}{r}1007.24 \\
446.00 \\
85.85\end{array}$ & $\begin{array}{c}11.73^{* * *} \\
5.19^{*} \\
-\end{array}$ \\
\hline
\end{tabular}

Tableau 1 : Analyse de variance des effets de la nature du dilueur et de la durée de la dilution du sperme dans le dilueur avant insémination. Données de la figure 1. 

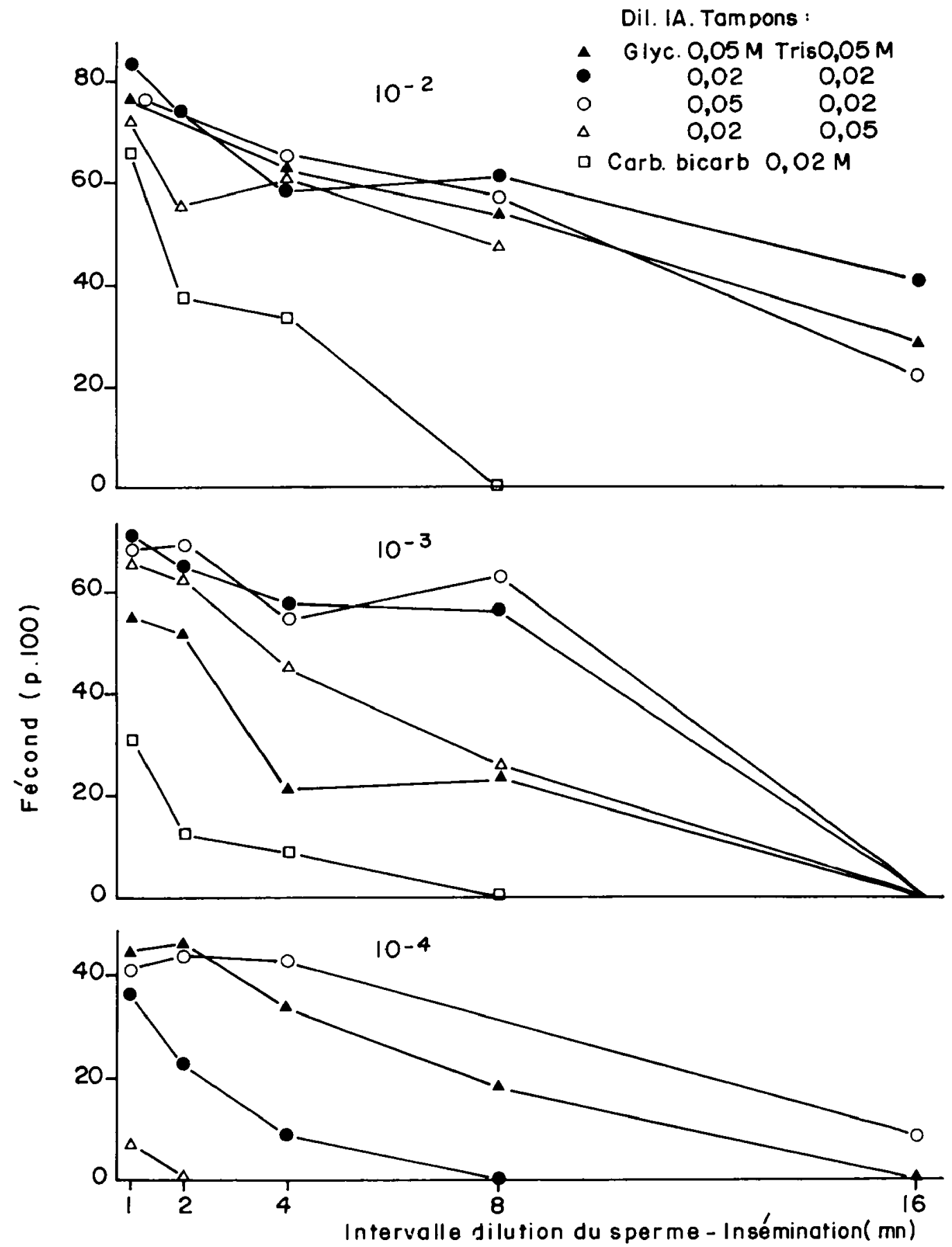

Figure 3 - Evolution du pouvoir fécondant du sperme après dilution dans différents milieux; technique de simple dilution; mèmes dilueurs que dans la figure 1. 
Le dilueur le plus favorable (glycocolle $0,05 \mathrm{M}$, Tris $0,02 \mathrm{M}$ : DIAxc) a été comparé avec d'autres milieux: plasma sanguin et milieu B 2 (Fig. 4). II apparait que ces deux derniers milieux, beaucoup plus complets, n'assurent pas une meilleure conservation que DIA tr. La comparaison de DIAtsi avec le liquide coelomique naturel est présentée dans la figure 5 . Le maintien de la survie des spermatozoìdes est aussi élevé dans le DIAra que dans le liquide coelomique, au moins pour des durées d'exposition ne dépassant pas 8 minutes. Pour les taux de dilution plus élevés $\left(10^{-4}\right)$, le DIAtg est même plus favorable au-delà de 8 minutes. La conservation est meilleure dans le liquide coelomique au moins pour les faibles dilutions $\left(10^{-2}\right)$

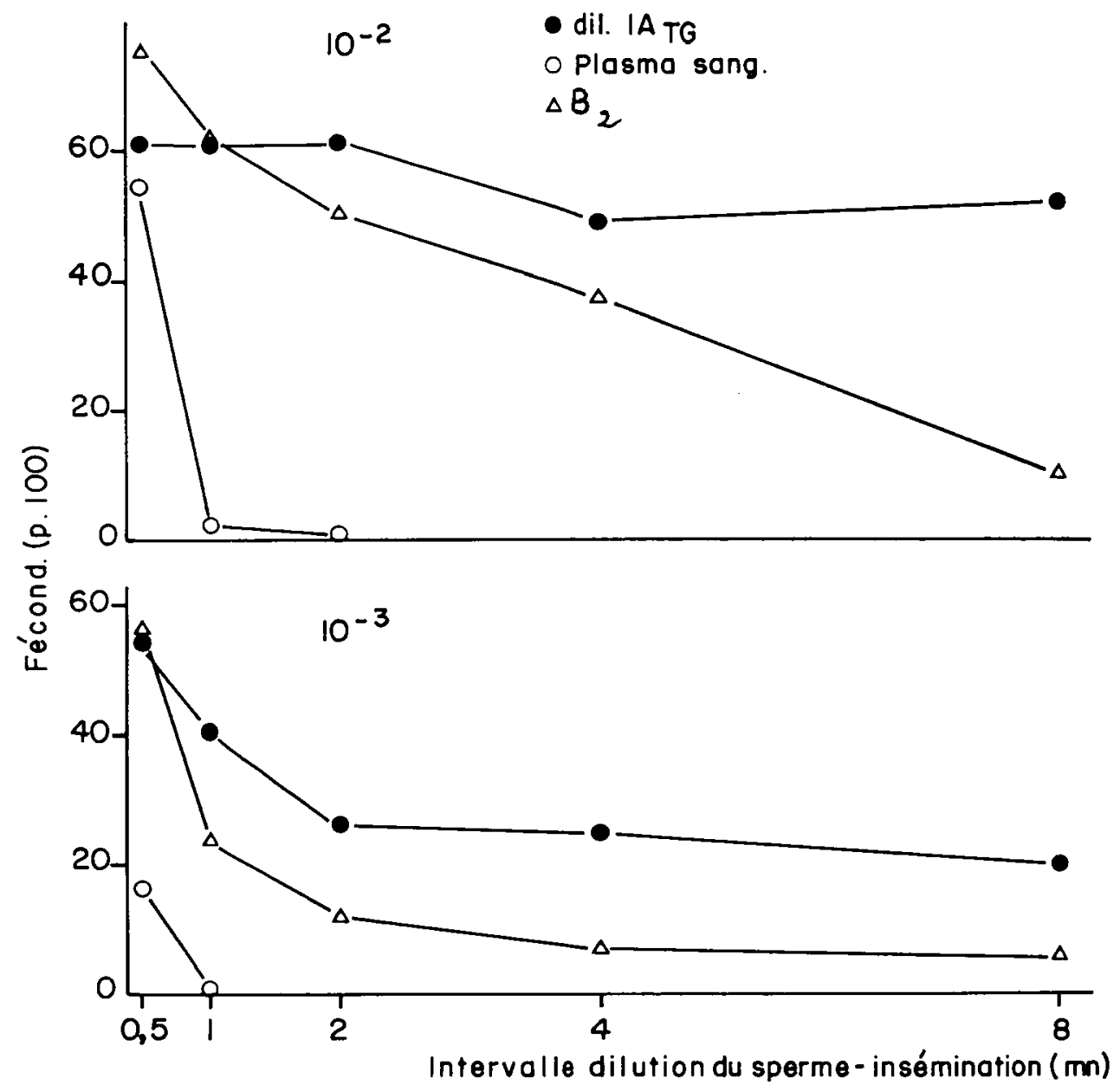

Figure 4 - Evolution du pouvoir fécondant du sperme après dilution dans le dilueur d'insémination tamponné par glycocolle $0.05 \mathrm{M}$ et Tris $0.02 \mathrm{M}$ (DIAts) $\bullet$ du plasma sanguin o et milieu balancé $\left.B_{2}\right\lrcorner$ (MENEZO, 1976). 
Dans une expérience complémentaire, la comparaison entre liquide coelomique et DIAxc a été faite par les techniques de simple et double dilutions. Dans la technique de simple dilution, utilisée dans les expériences précédentes, une partie des spermatozoides peut ne pas avoir èté mise en mouvement, surtout pour les faibles dilutions et ne l'est pas lors de l'addition du mélange spermedilueur aux œufs puisque l'insémination est pratiquée à sec. Dans le cas de la double dilution, les spermatozoïdes qui n'auraient pas été mis en mouvement lors de la première dilution le seront lors de l'insémination du fait de la dilution supplémentaire. Les résultats de la figure 1 confirment avec la technique de simple dilution la supériorité du liquide coelomique aux faibles dilutions et pour des périodes d'exposition prolongées. Avec le DIATsi la survie du sperme aux fortes dilutions est moins bonne que dans le cas précédent (Fig. 5). L'utilisation de la technique de double dilution ne modifie pas sensiblement les résultats en ce qui concerne le DIArg, mais on assiste avec le liquide coelomique à une prolongation du pouvoir fécondant, voire même à une reprise de ce pouvoir fécondant entre la $60^{\circ}$ et la $120^{\circ}$ minute d'exposition (Fig. 6).

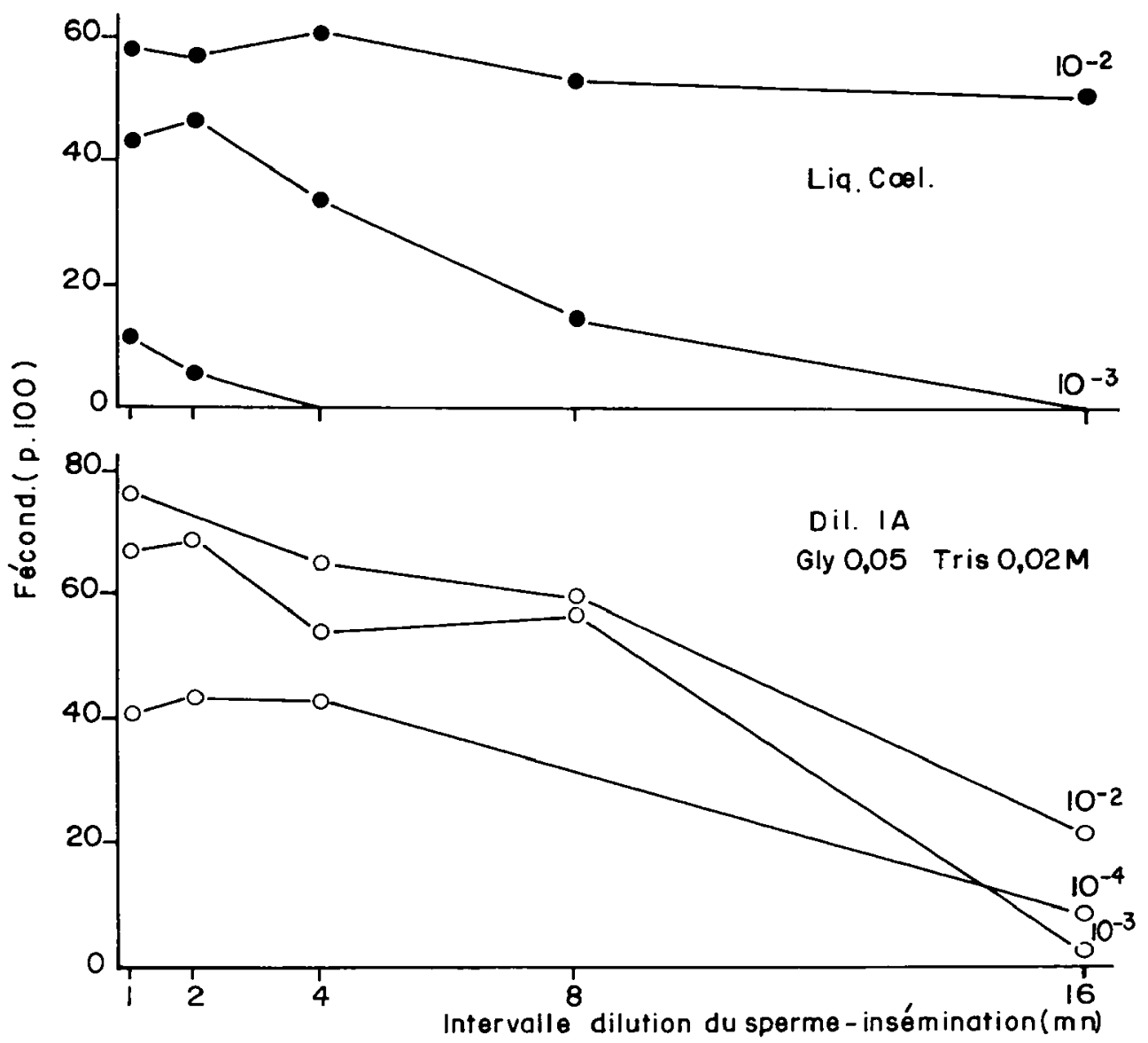

Figure 5 - Evolution du pouvoir fécondant du sperme dilué dans le DIA tr: et du liquide coelomique naturel; technique de simple dilution. 

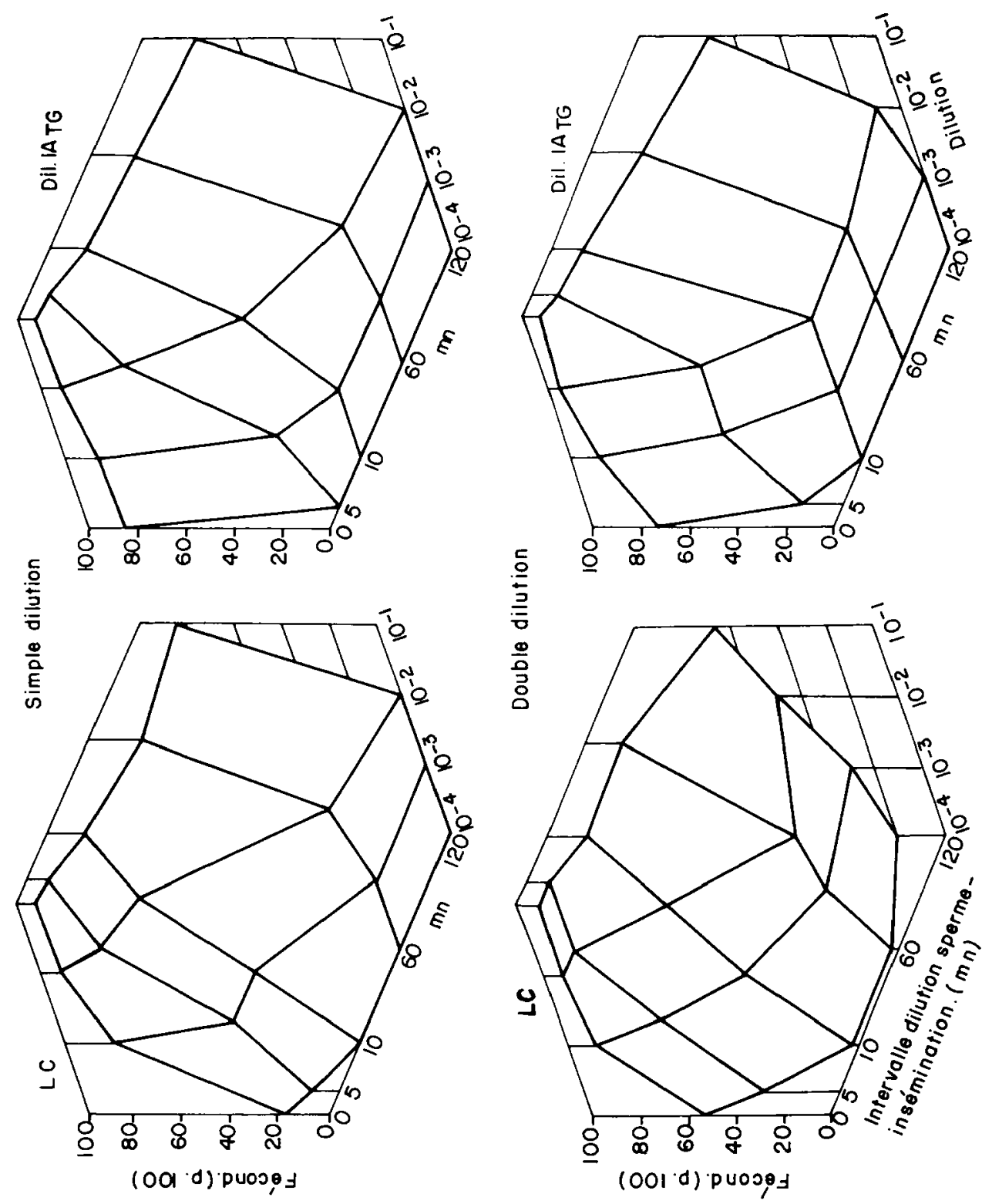

Figure 6 - Evolution du pouvoir fécondant du sperme dilué dans le DIAтs et du liquide cœlomique naturel; techniques de simple et double dilutions.

Lorsque le système glycocolle $0,05 \mathrm{M}$ et Tris $0,02 \mathrm{M}$ est utilisé pour tamponner un milieu plus complexe comme le MMLS dans lequel les spermatozoìdes restent immobiles après dilution, on constate (Fig 7) que la fécondance est conservée à son niveau initial pendant deux heures à condition que le taux de dilution ne dépasse pas $10^{-3}$. 


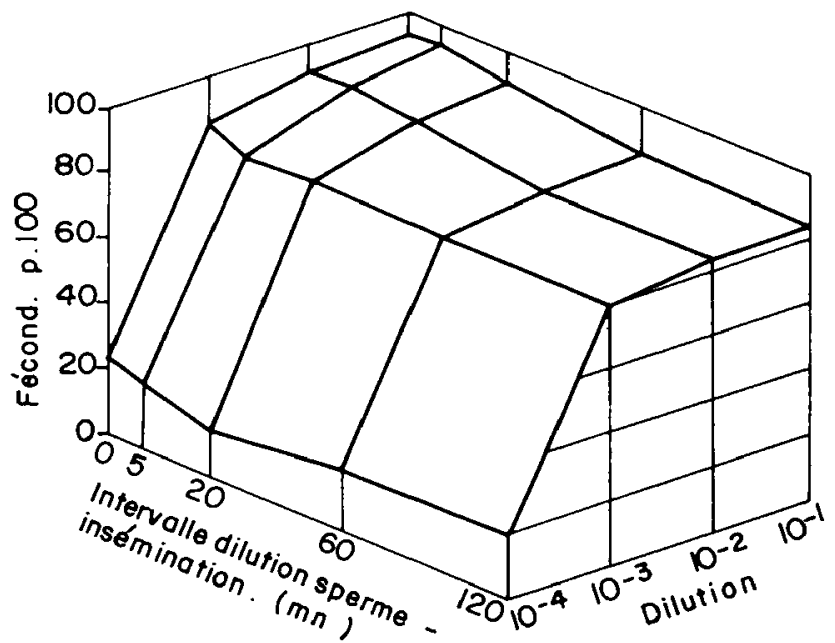

Figure 7 - Conservation du pouvoir fécondant du sperme dilué, mais maintenu immobile dans le MMLS tamponné avec glycocolle $0.05 \mathrm{M}$-Tris $0.02 \mathrm{M}$.

C. - Effet du DIAtri sur le pourcentage de fécondation d'ovules pollués par du vitellus

Le DIAтs a été comparé avec de l'eau dans le cas d'insémination d'un mélange d'ovules dans lequel un certain nombre ont été écrasés $(0-0,5-1$ et $2 \%$ ). Une telle situation peut se rencontrer dans les conditions de pisciculture où les ovules peuvent se trouver écrasés lors de la collecte, particulièrement. dans le cas de jeunes femelles ou de femelles dont les ovules sont fragiles. Lorsque ces ovules pollués par le vitellus sont mis en présence d'eau, il s'ensuit une précipitation et une agglutination des spermatozoides, phénomènes qui ne se produisent pas après dilution dans le DIA $\mathrm{Tr}_{\mathrm{r}}$. L'examen des pourcentages de fécondation obtenus (tableau 2), montre, dans le cas de dilution avec de l'eau douce, une diminution du pourcentage de fécondation que l'analyse statistique fait apparaitre hautement significative.

\begin{tabular}{|c|c|c|c|}
\hline \multirow{2}{*}{$\begin{array}{l}\% \text { d'ovules } \\
\text { écrasés }\end{array}$} & \multirow{2}{*}{$\begin{array}{c}\text { Taux de dilution } \\
\text { du sperme }\end{array}$} & \multicolumn{2}{|c|}{ Milieu d'insémination } \\
\hline & & eau & DIATg \\
\hline 0 & $\begin{array}{l}10^{-2} \\
10^{-3}\end{array}$ & $\begin{array}{l}67.6 \\
55.7\end{array}$ & $\begin{array}{l}86.1^{* \star *} \\
76.8^{\star * *}\end{array}$ \\
\hline 0,5 & $\begin{array}{l}10^{-2} \\
10^{-3} \\
\end{array}$ & $\begin{array}{l}44.1 \\
42.0\end{array}$ & $\begin{array}{l}84.2^{* * *} \\
83.5^{\star \star *}\end{array}$ \\
\hline 1,0 & $\begin{array}{l}10^{-2} \\
10^{-3}\end{array}$ & $\begin{array}{l}0 \\
0 \\
\end{array}$ & $\begin{array}{l}76.7 \\
68.6 \\
\end{array}$ \\
\hline 2,0 & $\begin{array}{l}10^{-2} \\
10^{3}\end{array}$ & $\begin{array}{c}0 \\
0 \\
\star \star \star\end{array}$ & $\begin{array}{r}75.3 \\
78.7 \\
\text { औ }\end{array}$ \\
\hline
\end{tabular}

Tableau 2: Effet du dilueur sur le succès de l'insémination lorsque les ovules sont pollués par du vitellus provenant d'ovules écrasés. Comparaison des pourcentages par test $X^{\mathbf{L}}$ corrigé.

***:P<0.001 *: $P<0.05$ 


\section{EISCUSSION ET CONCLUSION}

Le système Tris-glycocolle utilisé comme tampon de dilueur d'insémination, dont les paramètres essentiels (posm 250 et $\mathrm{pH}$ 9) ont été définis précèdemment (PETIT et al., 1973), se révèle au moins comparable en ce qui concerne les pourcentages de fécondation obtenus au système carbonate-bicarbonate (BILLARD et al., 1974).

Le glycocolle semble même avoir sur le maintien du pouvoir fécondant du sperme de truite dilué un effet supérieur à celui du carbonate-bicarbonate, bien que ce dernier puisse fournir du $\mathrm{CO}_{2}$ qui peut être fixé par le sperme de Saumon (MOUNIB et EISAN, 1966, 1968a) et de Morue (MOUNIB et EISAN, 1968b) et dont ur. effet favorable sur le métabolisme du sperme de Mammifères a été signalé (HUMPHREY et MANN, 1949). Mais un effet favorable du glycocolle a aussi été noté chez les Mammifères (FLIPSE, 1956 ; MENEZO, 1975, 1976) et pourrait être dû à un effet protecteur sur les membranes du spermatozoide (prévention de l'effet de dilution par exemple). Un effet analogue pourrait expliquer l'effet favorable du milieu B 2 (Fig. 4) qui contient $8 \mathrm{mM}$ de glycocolle et, d'autre part, le dilueur d'insémination utilisé peut favoriser le taux de fécondation en prévenant la précipitation des protéines ou lipoprotéines et l'agglutination des spermatozoìdes qui se produisent lorsque de l'eau est mis en présence de vitellus. Une pollution de la ponte par du vitellus provenant d'ovules écrasés est toujours possible dans la pratique, faisant appel à un prélèvement des ovules par massage abdominal, de sorte que l'insémination pratiquée avec de l'eau douce est susceptible de réduire notablement le pourcentage de fécondation. LEITRITZ (1962) a déjà signalé que des solutions salines simples pouvaient réduire ces phénomènes de précipitation. Dans le cas du DIA ti: cet effet favorable peut être amélioré par la grande variété des groupements hydrophiles et même lipophiles du Tris et du glycocolle.

En conclusion, l'association Tris-glycocolle semble donc pouvoir être proposée comme système tampon susceptible de stabiliser le $\mathrm{pH}$ du dilueur d'insémination.

\section{REMERCIEMENTS}

La présentation dactylographique du manuscrit est due à Jacqueline MARCEL. M. Yves MENEZO nous a aimablement fourni le milieu B 2 et a bien voulu lire ce document. Nous remercions aussi les laboratoires LATHEVET qui ont bien voulu assurer la fabrication du dilueur. Ce travail s'inscrit dans le cadre d'une collaboration contractuelle avec le Conseil Supérieur de la Pêche.

\section{RESUME}

Le $\mathrm{pH}$ du dilueur d'insémination pour Salmonidés peut être avantageusement stabilisé avec le système tampon Tris-glycocolie. Les molarités les plus favorables sont de $0,05 \mathrm{M}$ pour le glycocalle et $0,02 \mathrm{M}$ pour le Tris. Après dilution dans ce milieu (DIA $A_{\text {Ti }}$ ) le sperme conserve son pouvoir fécondant pendant $4 \mathrm{~min}$. (dilution $10^{-4}$ ) ou $8 \mathrm{~min}$. (dilution $10^{3}$ et $10^{\text {)}}$ ) alors que la dilution dans un milieu tamponné par le système carbonate bicarbonate entraine une chute de la fécondance après une minute.

Lorsque le DIA tr est employé pour l'insémination d'ovules pollués par du vitellus provenant d'ovules écrasés, le taux de fécondation est significativement plus élevé que si l'insémination est pratiquée avec de l'eau. 


\section{SUMMARY}

Use of the buffer system Tris-glycine to stabilize the $\mathrm{pH}$ of sperm diluent imoroves the effectiveness. The ideal concentration is $0.05 \mathrm{M}$ glycine and $002 \mathrm{M}$ Tris. Sperm diluted with this milieu (DIA $\mathrm{T}_{i}$ ) retain their ability to fertilize for $4 \mathrm{~min}$. (dilution $10^{-4}$ ) or $8 \mathrm{~min}$. (dilution $10^{-3}$ and $10^{-2}$ ) compared to only one min. using a buffer system of carbonate/bicarbonate.

When DIAT; is used for fertilization of eggs contaminated by yolk from damaged eggs, the fertilization success is significantly greater than that found using water.

\section{BIBLIOGRAPHIE}

BILLARD R., PETIT J., JALABERT B., SZÖLLÖSI D., 1974a. Artificial insemination in trout using a sperm diluent. Symposium on the early life history of fish. OBAN, Blaxter Edit., 715-723.

BILLARD R., JALABERT B., BRETON B., 1974b. L'insémination artificielle de la Truite (Salmo gairdneri Richardson). III - Définition de la nature et de la molarité du tampon à employer avec les dilueurs d'insémination et de conservation. Ann. Biol. anim. Bioch. Biophys., 14, 611-621.

BILLARD R., JALABERT B., 1974. L'insémination artificielle de la Truite (Salmo gairdneri Richardson). II - Comparaison des effets de differents dilueurs sur la conservation de la fertilité des gamètes avant et après insémination. Ann. Biol. anim. Bioch. Biophys., 14, 601-610.

FLIPSE R.J., 1956. Metabolism of glycine by bovine spermatozoa. Science, 124, 228.

HUMPHREY G.F., MANN T., 1949. Studies of metabolism of semen 5 citric acid in semen. Biochem. J., 44, 97-105.

LEITRITZ E., 1962. Trout and salmon culture (hatchery methods) in Fish bulletin no 107.

MENEZO Y., 1975. Amino-acid constituents of tubal and uterine f'uid of the cestrus ewe. Comparison with blood serum and ram seminal fluid. The Biology of spermatozoa in E.S.Z. Hafez et C.G. Thibault. Karger Ed., 174-181.

MENEZO Y., 1976. Milieu synthétique pour la survie et la maturation des gamètes et pour la culture de l'œuf fécondé. C.R. Acad. Sci., sous presse.

MOUNIB M.S., EISAN J.S., 1968b. Carbon dioxide fixation by spermatozoa of cod. glyoxylate by salmon sperm. Fed. Proc., 25, 314.

MOUNIB M.S., EISAN J.S., 1968a. Biosynthesis of lipids by salmon sperm from pyruvate, acetate and glyoxylate. Comp. Biochem. Physiol., 25, 193-200.

MOUNIB M.S., EISAN J.S., 1968b. Carbon d'oxide fixation by spermatozoa of cod. Comp. Biochem. Physiol., 25, 703-709.

PETIT J., JALABERT B., CHEVASSUS B., BILLARD R., 1973. L'insémination artificielle de la Truite (Salmo gairdneri Richardson). I - Effets du taux de dilution du $\mathrm{pH}$ et de la pression osmotique du dilueur sur la fécondation. Ann. Hydrobiol., 4, 201-210. 